\title{
Microstructure Characterization of Sn-Ag-Cu Lead-Free Solder Solidified at Different Cooling Speeds
}

\author{
A.R. Zbrzezny* \\ * University of Toronto, Materials Science and Engineering, Toronto, Canada, M5S 3E4
}

By altering the solidification speed of an alloy, one can control its microstructure and thus its mechanical properties to best suit a given application. In order to investigate this effect on the microstructure of $\mathrm{Sn}-\mathrm{Ag}-\mathrm{Cu}$ solder of near ternary eutectic composition [1] (Sn3.5wt\%Ag0.9\%wtCu), six different solidification schemes were investigated: 1) water quenching, 2) liquid nitrogen quenching, 3) air cooling, 4) hot plate cooling, 5) extremely slow unidirectional solidification, and 6) solder joint formation. The specimens were prepared using standard metallography techniques and then analyzed with optical microscopy, and SEM/EDX.

The fastest cooling rate was achieved with water quenching, which produced a highly dendritic microstructure with primary $\beta$-Sn dendrites, very fine interdendritic ternary eutectic, and no faceted intermetallic phases, Figure 1. The second fastest cooling with liquid nitrogen resulted in tin dendrites, an interdendritic $\mathrm{Sn}-\mathrm{Ag}_{3} \mathrm{Sn}$ binary eutectic, and faceted $\mathrm{Cu}_{6} \mathrm{Sn}_{5}$ intermetallic phase dispersed throughout the microstructure, Figure 2.

The microstructure of the air-cooled sample consisted of a mixture of two binary eutectics (Sn$\mathrm{Cu}_{6} \mathrm{Sn}_{5}$ and $\left.\mathrm{Sn}-\mathrm{Ag}_{3} \mathrm{Sn}\right)$, regions with ternary eutectic $\left(\mathrm{Sn}-\mathrm{Cu}_{6} \mathrm{Sn}_{5}-\mathrm{Ag}_{3} \mathrm{Sn}\right)$, and sizable $\mathrm{Cu}_{6} \mathrm{Sn}_{5}$ intermetallic compounds, often of the shape of hollow hexagonal prisms or disks, Figure 3.

Relatively slow solidification rate was realized during freezing of an alloy left on a hot plate, which had been turned-off immediately after melting. These cooling conditions were favorable for the formation of dendritic-like $\mathrm{Sn}-\mathrm{Ag}_{3} \mathrm{Sn}$ binary eutectic regions with ternary eutectic occupying the inderdentritic space. Although this sample was allowed more time to freeze, no large faceted intermetallic phases were present, Figure 4.

The samples, which had been unidirectionally solidified, exhibited significantly diverse regions in their microstructure. The exact nature of this solidification mechanism is still under investigation. Figure 5 shows a ternary eutectic area with fairly large intermetallics. Finally, in a practical application of wave soldering, a dendritic morphology was observed once again, Figure 6.

The current study demonstrated that a number of different structures could be obtained in response to different cooling conditions. It was shown that faster cooling rates produced an off-eutectic microstructure [2].

References:

[1] K.-W. Moon, et al., Experimental and Thermodynamic Assessment of Sn-Ag-Cu Solder Alloy, Journal of Electronic Materials, Vol 29, No. 10, 2000.

[2] Special thanks to P. Snugovsky and L. Snugovsky for their support. 


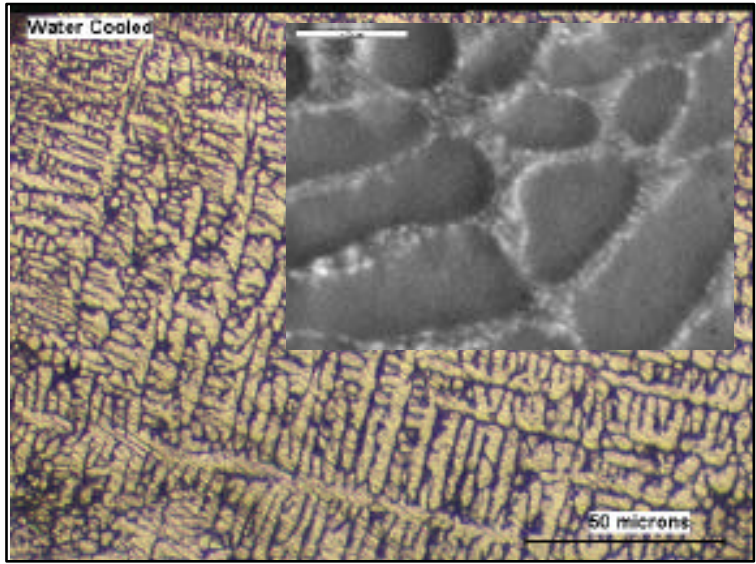

Figure 1. Water-cooled sample.

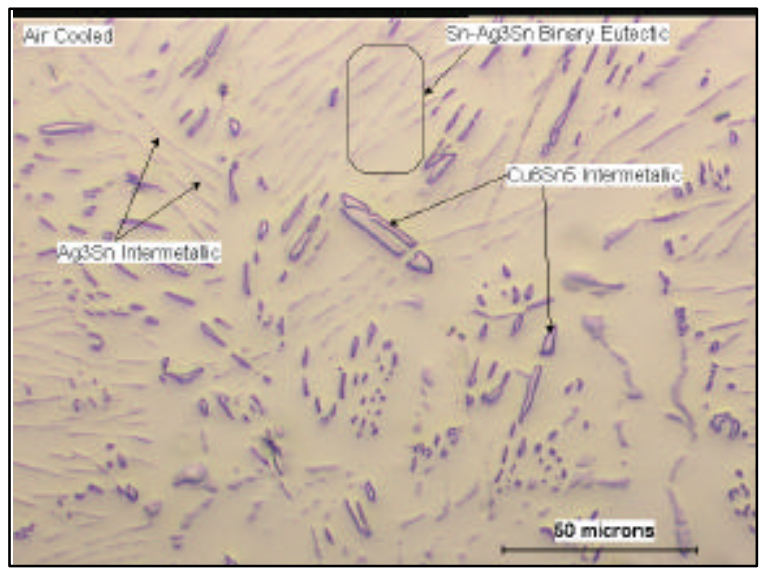

Figure 3. Air-cooled sample.

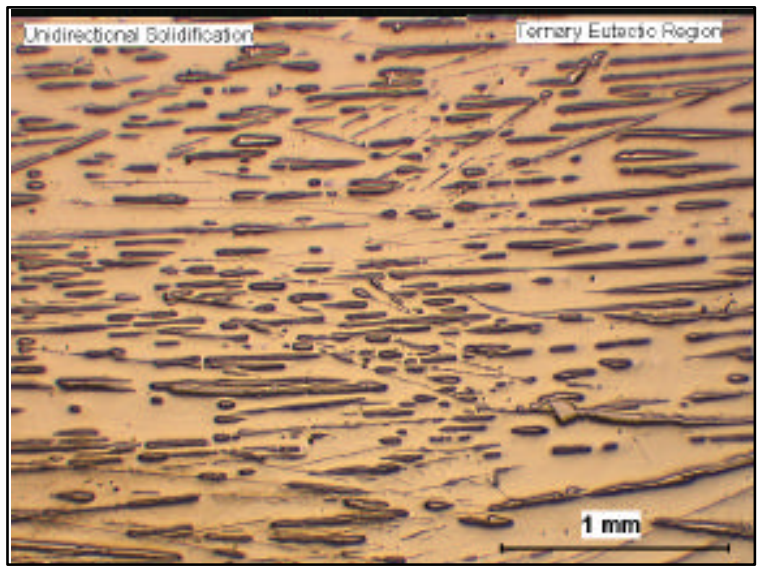

Figure 5. Unidirectional solidified sample.

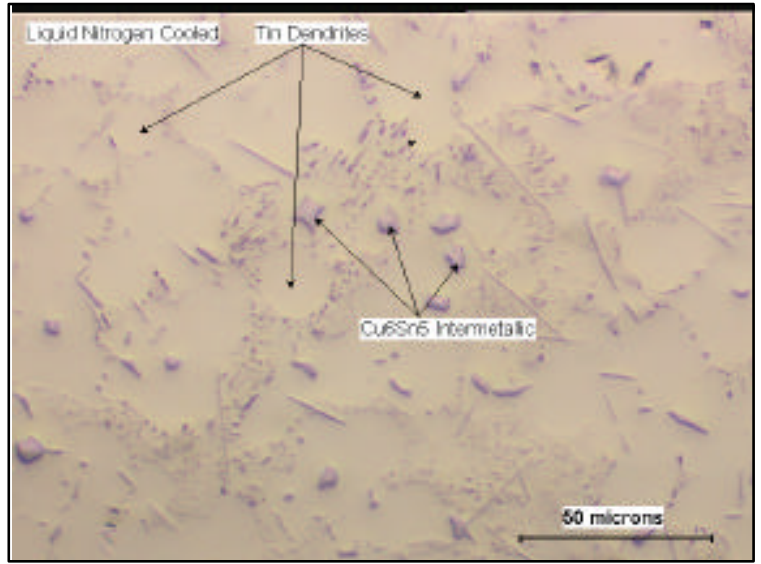

Figure 2. Liquid nitrogen cooled sample.

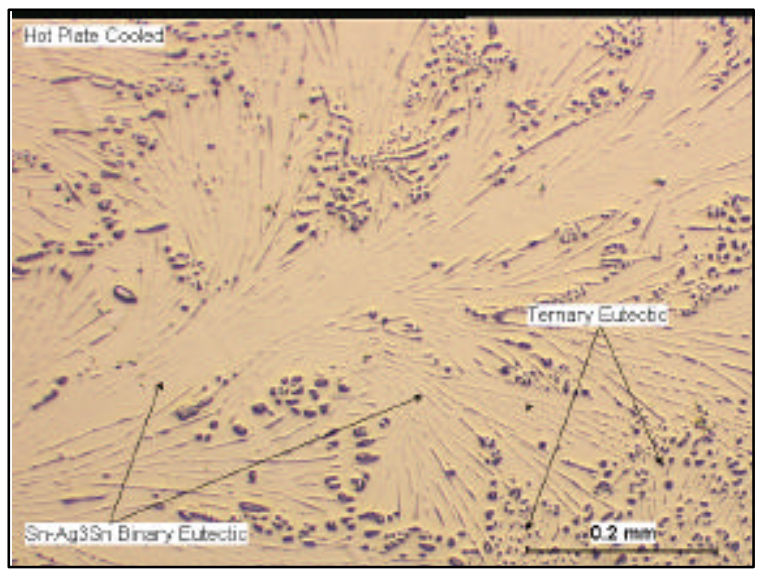

Figure 4. Sample cooled on hot plate.

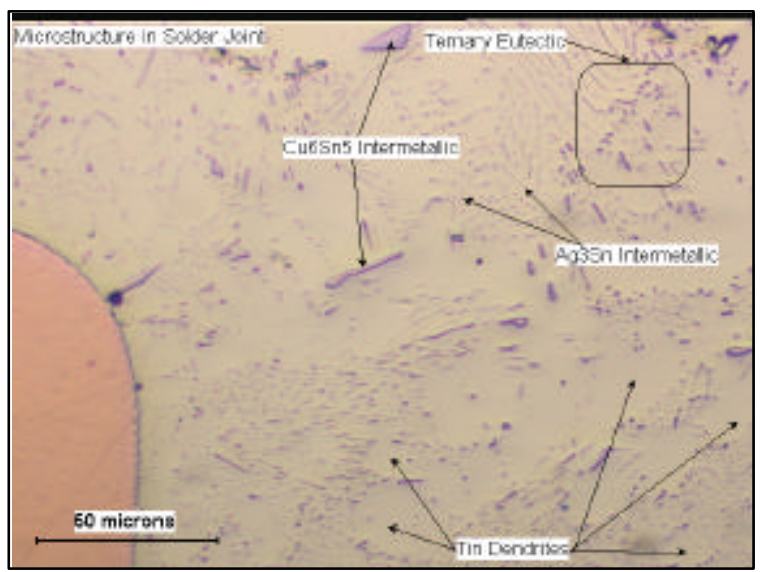

Figure 6. Solder joint. 